\title{
O USO DE RADAR DE PENETRAÇÃO DO SOLO (GPR) NA IDENTIFICAÇÃO DO LENÇOL FREATICO - PROJETO RENATURALIZAÇÃO DO RIO JACARE
}

Israeli Rodrigo Mathias dos Santos ${ }^{1}$, Eberton Rodriguês de Oliveira Neto ${ }^{1}$, Raquel Macedo Dias ${ }^{1}$, Felipe Monteiro dos Santos $^{1}$, Clara Pinto Ferreira Maia Porto ${ }^{1}$, Amanda Bourguignon Cecilio ${ }^{1}$, Juliana Fernandes Araujo ${ }^{1}$, Ana Luiza Muniz Lima $^{1}$, Julia Pires de Oliveira Machado ${ }^{1}$, Alberto G. Figueiredo $\mathrm{Jr}^{1}$, ${ }^{1}$ Departamento de Geologia e Geofísica, Universidade Federal Fluminense

\section{Copyright 2016, SBGf - Sociedade Brasileira de Geofísica}

Este texto foi preparado para a apresentação no VII Simpósio Brasileiro de Geofísica, Ouro Preto, 25 a 27 de outubro de 2016. Seu conteúdo foi revisado pelo Comitê Ouro Preto, 25 a 27 de outubro de 2016. Seu conteúdo foi revisado pelo Comitê de seus associados. É proibida a reprodução total ou parcial deste material para propósitos comerciais sem prévia autorização da SBGf.

\section{Abstract}

The research was conducted aiming to map and understand the dynamics of the water table in the Jacaré River basin, Piratininga District, city of Niterói, RJ, in order to suit a restoration project. This is an intermittent river that most of the year and much of its course has no running water.

The GPR survey was conducted to determine the depth of the water table and the interpretation of radargrams was adjusted according nearby water wells. Results show that water table is between 2.25 to $2.50 \mathrm{~m}$ depth

\section{Introdução}

A bacia do rio Jacaré está situada na região oceânica de Niterói, RJ, bairro de Piratininga/Jacaré, cobre uma área de $5,9 \mathrm{Km}^{2}$. O rio tem uma extensão de cerca de $5 \mathrm{Km}$ e uma vazão intermitente de maior parte de seu curso sem água durante maior parte do ano e pequena vazão na época das chuvas. Relatos históricos, no entanto, reportam abundância de água e ainda pesca neste rio.

Tendo em vista o propósito do Projeto de Renaturalização do Rio Jacaré, o entendimento da dinâmica de recarga e uma análise tanto qualitativa quanto quantitativa são de extrema importância para o estudo de viabilidade da proposta.

O levantamento do lençol freático está sendo feito pela equipe de Geologia e Geofísica do Instituto de Geociências da UFF e tem como objetivo a caracterização hidrológica e condições do lençol freático na bacia do rio Jacaré.

O lençol freático da Bacia do Jacaré é supostamente um aquífero fraturado, predominante na região Nordeste, Norte e Sudeste do Brasil e normalmente constituídos por litotipos pré-cambrianos, como, gnaisses, xistos, filitos, granitos, metacalcários, quartzito e basaltos. (Ribeiro at al 2014, apud Rebouças, 2002).

\section{Metodologia/ Problema Investigado}

Foi utilizado GPR com antena de $400 \mathrm{MHz}$ de fabricação da GSSI. Para o processamento do dado se fez uso de software Radan 6.6 adotando Constante Dielétrica de $0,07 \mathrm{~m} / \mathrm{ns}$ (ou $7 \times 10^{7} \mathrm{~m} / \mathrm{s}$ ), normalmente utilizada para solo argiloso saturado. Além disso, foi mapeado o nível d'água de poços e cisternas.
Foram levantadas um total de 06 linhas de GPR para identificação do nível d'água em sub-superfície na área da Hípica (Figs. 1 A e B).
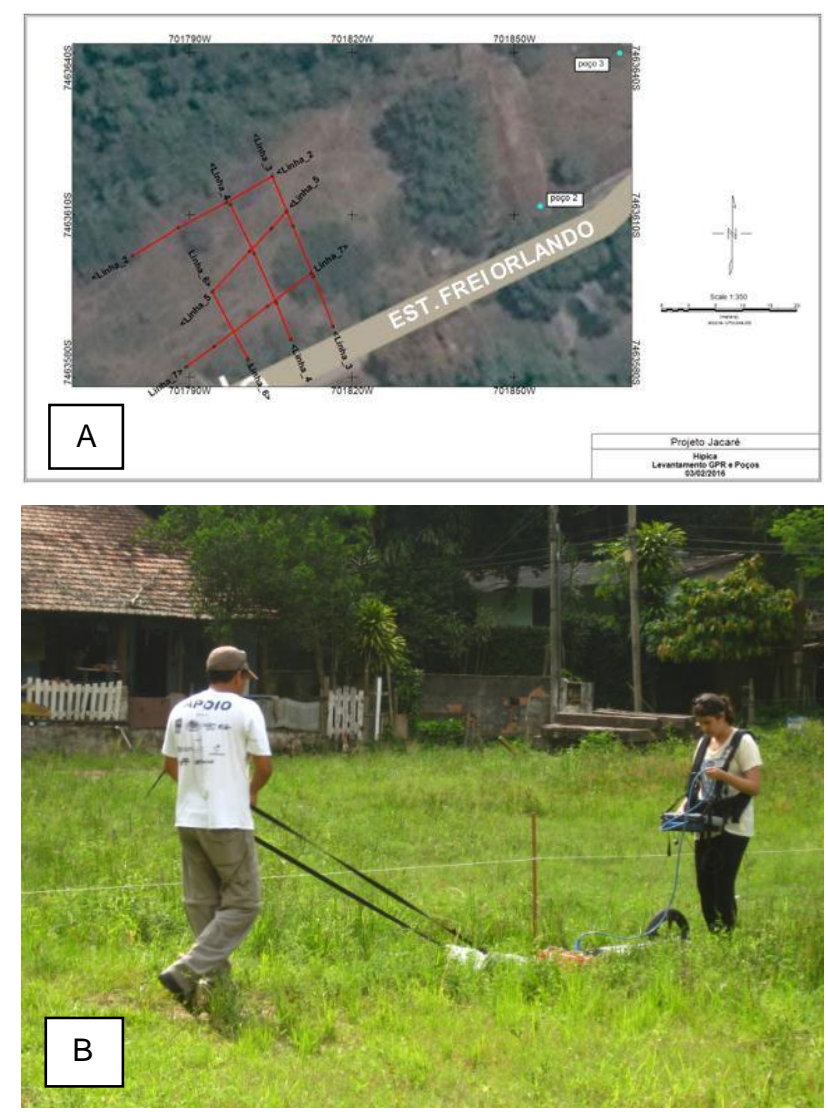

Figuras $1 A$ e $B$. Em $1 A$ pode ser vista a malha amostral e a localização dos poços de água na área da Hípica com linhas paralelas e linhas de intersecção. Em 1B o aspecto da situação de campo.

\section{Resultados}

De forma geral todas as linhas apresentaram o mesmo comportamento, portanto para fins práticos serão apresentadas apenas 3 linhas adquiridas na local da Hípica (Figs. 2 A e B). 


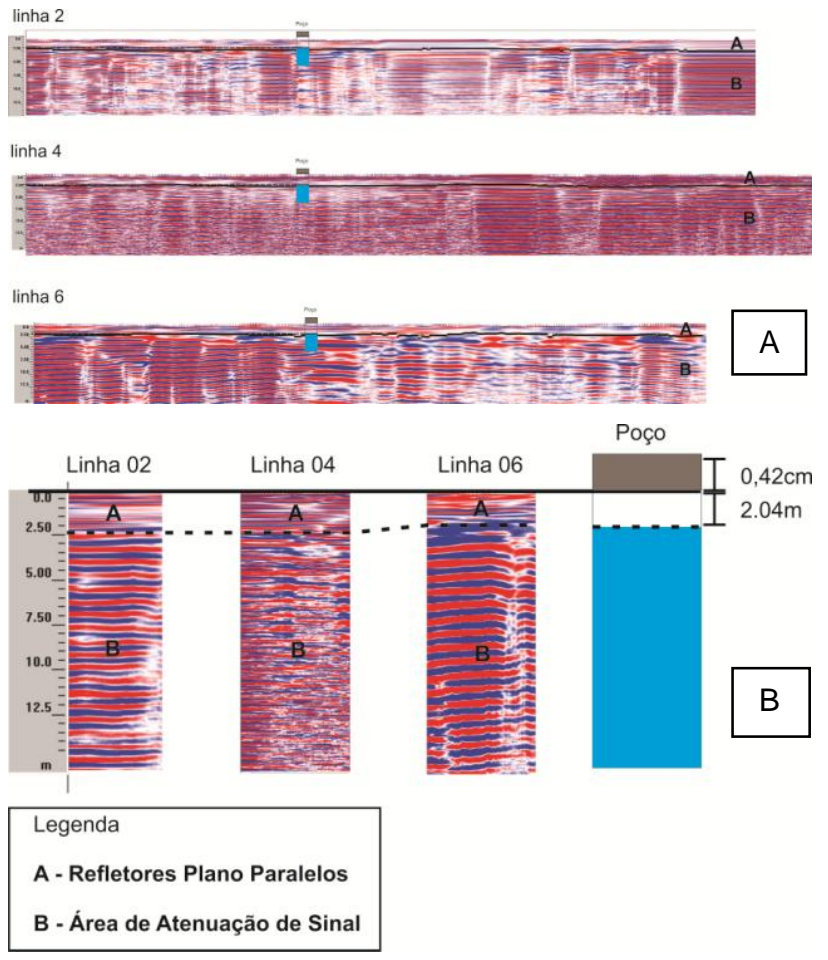

Figuras $2 A$ e $B-E m 2 A$ aspecto geral dos radargramas mostrando o posicionamento do lençol freático $e$ correlação com os poços de água. Em $2 B$ recorte de três e sua correlação com o poço proximo.

Os radargramas foram interpretados como constituídos de dois pacotes de sedimento. O pacote $A$ não saturado e B saturado, ambos apresentando uma boa correlação com o nível de água de um poço. O poço possuí $5,38 \mathrm{~m}$ metros de profundidade e a superfície d'água (nível do freático) encontrava-se 2,04 metros abaixo do nível do solo.

Em todas as linhas foram identificados dois pacotes distintos, como não é possível inferir com certeza sobre sua constituição litológica foram chamados de pacote $A$ e pacote B. Acredita-se que o pacote A, o mais raso, se trata do solo não saturado, enquanto, após o refletor limítrofe, identificado como lençol freático o solo passe a ser saturado, constituindo o pacote B, situado em uma zona de atenuação de sinal e perda de resolução, típicos da zona freática.

Nas linhas 2, 3 e 4 a cota do nível freático variou de 2,25 à 2,50 metros de profundidade. Mostrando boa correlação com os dados de poço.

\section{Discussão e Conclusões}

Um dos resultados que chama a atenção é a diferença de profundidade do lençol freático entre as medições de poço e os radargramas. Estas diferenças estiveram na ordem máxima de $40 \mathrm{~cm}$, e mínima de $20 \mathrm{~cm}$. Estas pequenas diferenças podem sem explicadas pela hidrodinâmica, já que o lençol freático nos poços está sobre a pressão atmosférica, enquanto o que está sob o solo (investigado pelo GPR) tem uma pressão excedente da pressão atmosférica onde esta pressão excedente é, $\rho_{\text {solo }} \times \mathrm{g} \times \mathrm{h}$, sendo $\rho$ a densidade do solo, $\mathrm{g}$, a aceleração da gravidade, e $\mathrm{h}$ a profundidade a partir do nível do solo. Por motivos hidráulicos, esta maior pressão precisa ser compensada, isto irá causar um rebaixamento natural do nível d'água em subsuperfície investigado no radargrama relativo ao nível d'água nos poços, podendo fazer com que estas diferenças encontrada entre o levanto de GPR e as medidas nos poços estejam dentro da margem de rebaixamento hidráulico natural.

A dinâmica hídrica do sistema como um todo ainda é desconhecida, porém com a adição de novos dados, possíveis resoluções vão sendo montadas. Muito se adquiriu de compreendimento do sistema e esclarecimento de dúvidas sobre o lençol freático nesta área. Novos levantamentos serão realizados permitindo comparar a variação do lençol freático de acordo com a recarga por precipitação em diferentes seções do Rio. Outros métodos como o de eletro-resistividade também deverão ser usados para inferir a litologia, espessura da zona freática, e qualidade d'água em sub-superfície.

\section{Agradecimentos}

À Prefeitura Municipal de Niterói, aos Instituto de Geociências da UFF e financiadores do projeto por tornarem possível a realização deste estudo de caso. Aos professores da UFF envolvidos neste projeto multidisciplinar e que se dispuseram a compartilhar de seus resultados e conhecimentos, fazendo com que estes servissem para complementação do nosso estudo. Aos proprietários dos sítios e terrenos visitados ao longo das campanhas, pela ajuda, compreensão e hospitalidade ao nos receberem dentro de suas posses e aos guias de campo, moradores do Bairro Jacaré, por nos ajudarem durante as idas à campo.

\section{Referências}

RIBEIRO, João Pedro Marques, VELÀSQUEZ, Leila Nunes Menegasse, CARVALHO FILHO, Carlos Alberto, FLEMING, Peter Marshall. 2014. Análise da recarga no sistema aquífero granular e fissural na área do Campus Pampulha da Universidade Federal de Minas Gerais. Geonomos, Belo Horizonte, vol 22, p.28-43. 